\title{
Erratum to: Approximate Controllability of Nonlocal Neutral Fractional Integro-Differential Equations with Finite Delay
}

\author{
Kamal Jeet $^{1} \cdot$ D. Bahuguna ${ }^{1}$
}

Published online: 4 June 2016

(C) Springer Science+Business Media New York 2016

\section{Erratum to: J Dyn Control Syst \\ DOI 10.1007/s10883-015-9297-0}

The original version of this article unfortunately contained a mistake. The name of "Kamal Jeet" is now corrected in the author group of this article.

The online version of the original article can be found at http://dx.doi.org/10.1007/s10883-015-9297-0.

\section{Kamal Jeet}

kamaljeetp2@gmail.com

1 Department of Mathematics \& Statistics, Indian Institute of Technology-Kanpur, Kanpur 208016, India 